\title{
Social inequalities in road traffic deaths at age 16-20 years among all 611654 Norwegians born between 1967 and 1976: a multilevel analysis
}

\author{
Petter Kristensen, ${ }^{1,2}$ Thomas Kristiansen, ${ }^{3}$ Marius Rehn, ${ }^{3,4}$ Hans Magne Gravseth, ${ }^{2}$ \\ Tor Bjerkedal ${ }^{1,5}$
}

${ }^{1}$ Department of Community Medicine, Institute of Health and Society, University of Oslo, Oslo, Norway

${ }^{2}$ Department of Occupationa Medicine and Epidemiology,

National Institute of Occupational Health, Oslo, Norway

${ }^{3}$ Department of Research, Norwegian Air Ambulance Foundation, Drøbak, Norway ${ }^{4}$ Akershus University Hospital, Lørenskog, Norway ${ }^{5}$ Institute of Epidemiology, Norwegian Armed Forces Medical Services, Oslo, Norway

\section{Correspondence to}

Petter Kristensen, National Institute of Occupational Health, P0 Box 8149 Dep, N-0033 Oslo, Norway;

petter.kristensen@stami.no

Accepted 13 April 2011

Published Online First

23 May 2011

\section{(2) UNLOCK:}

This paper is freely available online under the BMJ Journals unlocked scheme, see http:// injuryprevention.bmj.com/site/ about/unlocked.xhtml

\section{ABSTRACT}

Background Road traffic injury is a major cause of death among youths.

Aims To estimate mortality differences in family socioeconomic position (SEP) and municipal disadvantage level.

Methods Data on all Norwegians born in 1967-76, gathered from national registries, were linked by a unique national identification number. The 611654 participants were followed-up for 5 years from age 16 years. Parental education level, father's income level, and proportion of high-income earners in the municipality served as SEP indicators. Associations between SEP and road traffic deaths were analysed by multilevel Poisson regression.

Results Road traffic deaths $(n=676$, rate 22.2 per 100000 person-years) constituted a major cause of death, of which $91.9 \%$ were motor vehicle occupants. SEP distributions differed according to gender and type of motor vehicle crash (collision, non-collision). There was an inverse relationship between municipal proportions of high-income earners and mortality (population attributable fraction (PAF) $0.43,95 \% \mathrm{Cl} 0.30$ to 0.53 ) in all categories of gender-specific crash types. Family SEP gradients were not found except for male non-collision deaths, where increasing mortality was found in association with decreasing parental education level (PAF 0.94, 95\% Cl 0.59 to 0.99) and increasing paternal income (PAF $0.25,95 \% \mathrm{Cl} 0.06$ to 0.40 ). Conclusion The different SEP patterns for road traffic deaths across gender and motor vehicle crash type illustrate that heterogeneity of social inequalities in health can be found even within narrow age bands and for similar causes of death.

Road traffic injury is a major public health problem worldwide and those most at risk are consistently the economically deprived. ${ }^{1}$ The death toll is largest in developing countries, ${ }^{1}$ but road traffic injury is still the leading cause of injury death in developed countries and socioeconomic gradients are not decreasing. ${ }^{2-4}$

Injury epidemiology addressing social inequalities applies explanatory models that include both individual and contextual factors. ${ }^{4-10}$ However, epidemiological studies addressing both individual and area indicators of socioeconomic position (SEP) in multilevel analysis are still few. ${ }^{8-10}$

Socioeconomic gradients in transport injuries have been documented in several reviews ${ }^{1-6}$ and numerous studies. ${ }^{8-20}$ Among these, several studies were restricted to youths or performed separate analyses among adolescents and young adults. ${ }^{10-18}$ SEP indicators in studies covering adolescents have mostly been family based-for example, parental occupational class, education level, and income. Family occupational class, education, and income were interrelated in a Swedish study addressing SEP gradients among young car drivers, and education had a slightly higher impact on road traffic injuries than occupation, whereas income had only marginal impact. ${ }^{14}$ There are no consistent results concerning area level SEP indicators. ${ }^{8-10}$ In the US National Health Interview Survey, motor vehicle deaths in a broad age range were associated with neighbourhood poverty, low income, blue collar occupation, and low education. ${ }^{9}$

There are several indications that social inequalities in road traffic injuries vary across age, gender, road user type, and category of injury. In general, equalisation in SEP gradients is found in youth. ${ }^{21}{ }^{22}$ However, road traffic injury data in Sweden, restricted to those aged 2-24 years, suggest that differentials increase at the age when young people start using motorised vehicles. ${ }^{11}$ In general, social inequalities in health have been found to be steeper for males than females, but this has not been confirmed for road traffic injuries. ${ }^{3}{ }^{11}$ There is also variation in socioeconomic disparities among youths according to injury cause, ${ }^{10}$ with larger differences for injuries among motor vehicle occupants $^{11}$ and specific motor vehicle crash circumstances. $^{12}$ Such heterogeneity of social inequalities in road traffic injuries has not been extensively studied, but should not be unexpected considering the intricate causal pathways linking social factors and health. ${ }^{21} 23$

We have established a register-based cohort comprising all live-born in Norway during $1967-76,{ }^{24}$ including repeated individual and area characteristics recorded throughout life. Road traffic mortality in this cohort was at its highest between ages 16 and 20 (figure 1). This overlaps with the age when licensed driving is first permitted, which is 16 years for lightweight motorcycle riders and 18 years for car drivers. We decided to restrict the follow-up to the five highrisk years between ages 16 and 20. The main objective was to investigate socioeconomic differentials in road traffic mortality on the individual and community level according to gender, road user type, and injury type. We expected steeper socioeconomic gradients for males than for females. We also anticipated that residents in economically disadvantaged areas would be at increased risk. 


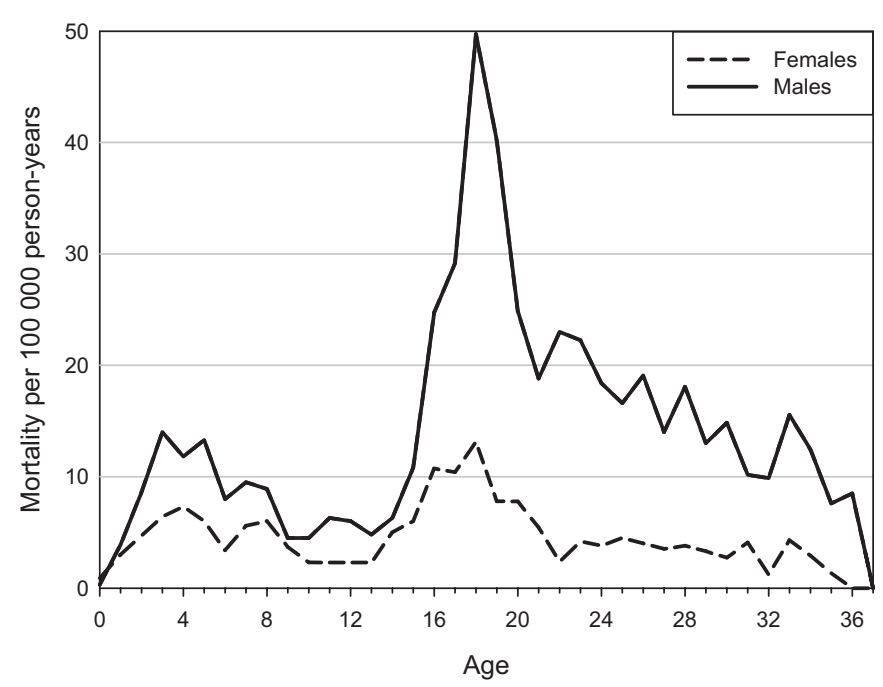

Figure 1 Age-specific fatal road traffic injuries according to gender among 626928 persons born in Norway between 1967 and 1976.

\section{METHODS}

\section{Participants and data collection}

The study population was based on all 626928 live births in the Medical Birth Registry of Norway born between 1967 and 1976. All who died $(1.8 \%)$ or emigrated $(0.7 \%)$ before their 16 th birthday were excluded from analysis; the remaining 611654 constituted the study participants. The unique national identification number allowed linkage with national registries in Statistics Norway: the Cause of Death Register, the National Education Database, and the Central Population Register. The Norwegian Labour and Welfare Administration provided data on father's income. Aggregate municipal level data were retrieved from the regional database of the Norwegian Social Science Data Services (https://trygg.nsd.uib.no/nsd/english/regionaldata.html). The Regional Committee for Medical Research Ethics approved the study (ref no. S-06028).

\section{Variables}

The linkage enabled us to construct a file with individual and municipal data collected from birth onwards, with the participant as the observational unit.

Based on a priori hypotheses, we decided to include parental education and income level as family SEP indicators. Other individual independent variables were year of birth, gender, and mother's marital status. Parental education was based on the Norwegian standard NUS2000 (http://www.ssb.no/english/ subjects/04/90/nos_c751_en/nos_c751_en.pdf). Parental level in the year of the participant's 16th birthday was collapsed from nine into five ordinal categories depending on the parent with the highest educational level. Father's mean annual income during participant age $7-15$ years was categorised into quartiles. Annual pensionable income was recorded by the Labour and Welfare Administration in units that are adjusted regularly in accordance with changes in the general income level. Father's income was missing when his identity was not included in the birth record. Mother's marital status at participant age 16 years was dichotomised (married/unmarried).

Residence at age 16 was coded according to Statistics Norway's classification into 435 municipalities. Municipalities are the smallest administrative unit of local government in Norway. Their responsibilities include social services, economic development, and municipal roads. Among several municipal indicators of socioeconomic level constructed on the basis of information in the Norwegian Social Science Data Services, we found that the proportion of all income earners who paid surtax to the state in 2000 and the proportion of inhabitants with tertiary education in 1990 were most strongly associated with road traffic mortality. Analyses with both these indicators resulted in collinearity as they correlated strongly (correlation coefficient 0.825 ). We therefore decided to use the variable with the strongest correlation with road traffic mortality, which was proportion of high-income earners. The variable was categorised in quartiles, with decreasing high-income earners indicating municipal disadvantage.

Higher road traffic death rates have been found in rural areas than urban areas in a number of studies. ${ }^{9} 1325$ We therefore applied municipal urbanisation based on Statistic Norway's standard classification of centrality (http://www3.ssb.no/ stabas/ItemsFrames.asp? ID=5290001\&Language=en), classifying 232 municipalities as urban and 203 as rural. A municipality was defined as rural if travelling to an urban settlement took at least 45 min, according to Statistics Norway's standard.

Distribution of the independent individual and municipal variables that were applied in the analyses is provided in table 1.

The main study outcome was death from a road traffic injury, notified during follow-up. The Cause of Death Register used ICD-8, ICD-9, and ICD-10 during the study period. Codes according to road user type are specified in table 2. Occupant deaths following motor vehicle crashes were also considered according to crash category. Non-collision deaths represent events due to loss of control on the road (ICD-8 E816, ICD-9 E816, ICD-10 V28/V48), excluding vehicle-to-vehicle impact. The remaining motor vehicle crashes were termed collision crashes.

\section{Statistical analysis}

We used Stata/SE 11.1 software. Person-time at risk was computed for each participant during follow-up, or death or emigration, whichever occurred first.

Death rates due to road traffic injuries with subgroups according to road user type were computed per 100000 personyears at risk. Rate ratio (RR) with accompanying 95\% CI was estimated in multilevel mixed effects Poisson regression models, applying Stata's xtmepoisson option with a random intercept without any random coefficients. Models included five individual-level and two municipality-level variables: year of birth (continuous), gender, parental education (five levels), father's income level (quartiles), mother's marital status (dichotomous), high-income earners in municipality (quartiles), and municipal urbanisation (dichotomous). Missing values for individual characteristics were included as separate categories, but because the xtmepoisson regression did not converge for cells with zero deaths we had to omit participants with missing parental education level.

We also computed adjusted population attributable fraction (PAF) for the socioeconomic indicators (parental education, father's income, and high-income earners in the municipality) using ordinary Poisson regression and Stata's aflogit procedure. Here, dummy variables were applied for all values except the reference value, which were tertiary high parental education, the lowest quartile of father's income, and the highest quartile of municipal high-income earners. Observations with missing data for the predictor were excluded.

\section{RESULTS}

\section{Road traffic mortality}

The total follow-up counted 3047849 person-years (mean 4.98 years). During follow-up, 3787 participants emigrated and 
Table 1 Distribution of descriptive characteristics and road traffic deaths for 611654 Norwegians born between 1967 and 1976 and followed-up from age 16 to 20 years

\begin{tabular}{|c|c|c|c|c|}
\hline Characteristic & No. & $\%$ & $\begin{array}{l}\text { No. of } \\
\text { deaths }\end{array}$ & Rate \\
\hline \multicolumn{5}{|l|}{ Individual level variables } \\
\hline \multicolumn{5}{|l|}{ Gender } \\
\hline Females & 298466 & 48.8 & 149 & 10.0 \\
\hline Males & 313188 & 51.2 & 527 & 33.8 \\
\hline \multicolumn{5}{|l|}{ Year of birth } \\
\hline 1967-68 & 130136 & 21.3 & 192 & 29.6 \\
\hline $1969-70$ & 129069 & 21.1 & 172 & 26.7 \\
\hline $1971-72$ & 126588 & 20.7 & 123 & 19.5 \\
\hline $1973-74$ & 118038 & 19.3 & 101 & 17.2 \\
\hline $1975-76$ & 107339 & 17.6 & 88 & 16.5 \\
\hline \multicolumn{5}{|l|}{ Parental education level } \\
\hline Tertiary, high (class level 17+) & 42811 & 7.0 & 22 & 10.3 \\
\hline Tertiary, low (class level 14-16) & 110226 & 18.0 & 70 & 12.7 \\
\hline $\begin{array}{l}\text { Upper secondary, complete (class } \\
\text { level } 12-13 \text { ) }\end{array}$ & 121336 & 19.8 & 133 & 22.0 \\
\hline $\begin{array}{l}\text { Upper secondary, basic (class level } \\
10-11 \text { ) }\end{array}$ & 244193 & 39.9 & 295 & 24.3 \\
\hline $\begin{array}{l}\text { Lower secondary or less (class level } \\
0-9 \text { ) }\end{array}$ & 91246 & 14.9 & 153 & 33.7 \\
\hline Missing & 1842 & 0.3 & 3 & 33.7 \\
\hline \multicolumn{5}{|l|}{ Father's income quartile } \\
\hline Highest & 142255 & 23.3 & 124 & 17.5 \\
\hline Third & 142274 & 23.3 & 147 & 20.8 \\
\hline Second & 142319 & 23.3 & 158 & 22.3 \\
\hline Lowest & 142283 & 23.3 & 188 & 26.5 \\
\hline Missing & 42523 & 7.0 & 59 & 28.4 \\
\hline \multicolumn{5}{|l|}{ Mother's marital status } \\
\hline Married & 501622 & 82.0 & 527 & 21.1 \\
\hline Unmarried & 102728 & 16.8 & 135 & 26.4 \\
\hline Missing & 7304 & 1.2 & 14 & 38.5 \\
\hline \multicolumn{5}{|l|}{ Municipal level variables (six missing) } \\
\hline \multicolumn{5}{|c|}{ Proportion high-income earners (quartiles) $†$} \\
\hline $0.280-0.402$ & 152280 & 24.9 & 97 & 12.8 \\
\hline $0.224-0.279$ & 152903 & 25.0 & 152 & 19.9 \\
\hline $0.177-0.223$ & 153955 & 25.2 & 196 & 25.6 \\
\hline $0.024-0.176$ & 152510 & 24.9 & 231 & 30.4 \\
\hline \multicolumn{5}{|l|}{ Urbanisation $\ddagger$} \\
\hline Urban & 506080 & 82.7 & 515 & 20.5 \\
\hline Rural & 105568 & 17.3 & 161 & 30.6 \\
\hline
\end{tabular}

*Deaths per 100000 person-years.

†Proportion of income earners who paid surtax to the state in 2000.

$\ddagger$ The municipality's geographical position in relation to an urban settlement.

1922 (rate 63.1) died. More than one-third of all deaths were related to road traffic incidents $(n=676$, rate 22.2). Crude road traffic mortality increased steeply by decreasing levels of parental education and municipal high-income earners whereas the association with decreasing paternal income was more moderate (table 1). Rates were also considerably higher among males and moderately higher for participants with unmarried mothers and those residing in rural municipalities.

The mortality distribution according to gender and road user category is shown in table 2 . Motor vehicle occupants $(n=621$, rate 20.4 ) constituted more than $90 \%$ of the total. Death rates were higher for men than for women in all road user categories, and the largest gender differences were found for motorcycle riders and car drivers. The highest male motorcycle rider mortality was found at age 16 (42 deaths, rate 13.5); 18-year-old males had the highest car driver mortality (82 deaths, rate 26.3). The proportion of deaths among motor vehicle occupants that were classified as non-collision was higher for males (0.525) than for females (0.445).

\section{Multivariate results}

Results for all road traffic deaths in the multilevel Poisson regression are provided in table 3 . Dose-dependent $R R$ increases were apparent for decreasing parental education level and decreasing levels of municipal high-income earners. Adjusted RRs for categories of paternal income were close to unity with a tendency of RRs below unity for low income. Separate analyses for males and females showed risk pattern differences. Notably, males had distinctive mortality increases in association with decreasing parental education level; such a pattern was absent for females. Decreasing levels of municipal highincome earners were associated with increasing mortality (PAF $0.43,95 \%$ CI 0.30 to 0.53 ). The females experienced only 149 deaths and the association estimates had wide confidence limits.

The relationship between SEP and mortality was examined in more detail by performing gender-specific analyses of non-collision and collision deaths (table 4). Additional analyses stratified on road user category (rider/driver, passenger) and motor vehicle type (car, motorcycle) did not alter the pattern in table 4 and are therefore not shown. Municipal disadvantage was more strongly associated with collision deaths than non-collision deaths for both genders, and female non-collision deaths lacked a consistent trend.

The family SEP indicators were not associated with the outcomes in the four subsets, with the exception of male noncollision deaths (table 4). Male non-collision mortality was strongly associated with decreasing parental education level with a more than 10-fold RR increase in the lowest level. Furthermore, male non-collision death was significantly lower in association with the lowest paternal income quartile.

Table 2 ICD codes for fatal road traffic injuries and number of deaths according to gender and road user type for 611654 Norwegians born between 1967 and 1976 and followed-up from age 16 to 20 years

\begin{tabular}{|c|c|c|c|c|c|c|c|}
\hline \multirow[b]{2}{*}{ Category } & \multirow[b]{2}{*}{ ICD-8 (1983-85) } & \multirow[b]{2}{*}{ ICD-9 (1986-95) } & \multirow[b]{2}{*}{ ICD-10 (1996-97) } & \multicolumn{2}{|c|}{ Females } & \multicolumn{2}{|c|}{ Males } \\
\hline & & & & No. & Rate* $^{*}$ & No. & Rate* $^{*}$ \\
\hline Total road traffic injuries & E810-E819, E825-E827 & E810-E819, E826-E829 & V01-V29, V40-V49 & 149 & 10.0 & 527 & 33.8 \\
\hline Car driver & Last digit 0 & Last digit 0 & V40-V49 last digit 5 & 43 & 2.9 & 210 & 13.5 \\
\hline Car passenger & Last digit 1 & Last digit 1 & V40-V49 last digit 6 & 68 & 4.6 & 139 & 8.9 \\
\hline Motorcycle rider & Last digit 2 & Last digit 2 & V20-V29 last digit 4 & 8 & 0.5 & 116 & 7.4 \\
\hline Motorcycle passenger & Last digit 3 & Last digit 3 & V20-V29 last digit 5 & 6 & 0.4 & 10 & 0.6 \\
\hline Unspecified motor vehicle occupant $†$ & E810-E819, last digit 9 & E810-E819, last digit 9 & V20-V29 or V40-V49, last digit 9 & 3 & 0.2 & 18 & 1.2 \\
\hline Other $\ddagger$ & & & & 21 & 1.4 & 34 & 2.1 \\
\hline
\end{tabular}

*Deaths per 100000 person-years.

+Motor vehicle category or status as driver/rider/passenger not specified.

$\ddagger$ Pedal cyclist $(n=6)$, pedestrian $(n=44)$, animal rider $(n=4)$, unspecified $(n=1)$.

ICD, International Classification of Disease. 
Table 3 Road traffic deaths $(n=676)$ according to gender, in association with individual and municipal characteristics, for 609807 Norwegians born between 1967 and 1976 and followed-up from age 16 to 20 years*

\begin{tabular}{|c|c|c|c|c|c|c|}
\hline \multirow[b]{2}{*}{ Characteristic } & \multicolumn{2}{|l|}{ Total } & \multicolumn{2}{|c|}{ Females } & \multicolumn{2}{|c|}{ Males } \\
\hline & $\mathbf{R R} †$ & $95 \% \mathrm{Cl}$ & $\mathbf{R R} \dagger$ & $95 \% \mathrm{Cl}$ & $\mathbf{R R} †$ & $95 \% \mathrm{Cl}$ \\
\hline \multicolumn{7}{|l|}{ Individual level variables } \\
\hline \multicolumn{7}{|l|}{ Gender } \\
\hline Female & 1 & Ref. & 1 & Ref. & 1 & Ref. \\
\hline Male & 3.35 & 2.79 to 4.01 & & & & \\
\hline Year of birth & 0.93 & 0.90 to 0.95 & 0.94 & 0.87 to 1.01 & 0.92 & 0.89 to 0.96 \\
\hline \multicolumn{7}{|l|}{ Parental education level } \\
\hline Tertiary, high & 1 & Ref. & 1 & Ref. & 1 & Ref. \\
\hline Tertiary, low & 1.17 & 0.72 to 1.91 & 0.78 & 0.33 to 1.82 & 1.41 & 0.77 to 2.56 \\
\hline $\begin{array}{l}\text { Upper secondary, } \\
\text { complete }\end{array}$ & 2.01 & 1.27 to 3.20 & 1.12 & 0.49 to 2.53 & 2.55 & 1.44 to 4.52 \\
\hline Upper secondary, basic & 2.04 & 1.29 to 3.22 & 1.18 & 0.53 to 2.61 & 2.56 & 1.46 to 4.51 \\
\hline Lower secondary or less & 2.66 & 1.65 to 4.28 & 1.12 & 0.47 to 2.66 & 3.63 & 2.03 to 6.49 \\
\hline \multicolumn{7}{|l|}{ Father's income quartile } \\
\hline Highest & 1 & Ref. & 1 & Ref. & 1 & Ref. \\
\hline Third & 0.89 & 0.69 to 1.14 & 1.12 & 0.67 to 1.90 & 0.83 & 0.62 to 1.10 \\
\hline Second & 0.80 & 0.62 to 1.03 & 0.67 & 0.37 to 1.21 & 0.82 & 0.62 to 1.09 \\
\hline Lowest & 0.85 & 0.66 to 1.09 & 1.31 & 0.77 to 2.23 & 0.74 & 0.55 to 0.99 \\
\hline Missing & 1.08 & 0.77 to 1.51 & 1.17 & 0.56 to 2.43 & 1.04 & 0.71 to 1.52 \\
\hline \multicolumn{7}{|l|}{ Mother's marital status } \\
\hline Married & 1 & Ref. & 1 & Ref. & 1 & Ref. \\
\hline Unmarried & 1.31 & 1.07 to 1.59 & 1.31 & 0.87 to 1.96 & 1.30 & 1.04 to 1.63 \\
\hline Missing & 1.59 & 0.93 to 2.71 & 0.53 & 0.07 to 3.79 & 1.88 & 1.07 to 3.28 \\
\hline \multicolumn{7}{|l|}{ Municipal level variables } \\
\hline \multicolumn{7}{|c|}{ Proportion high-income earners (quartiles) } \\
\hline Highest & 1 & Ref. & 1 & Ref. & 1 & Ref. \\
\hline Third & 1.41 & 1.01 to 1.97 & 1.84 & 1.04 to 3.25 & 1.36 & 0.96 to 1.94 \\
\hline Second & 1.72 & 1.24 to 2.38 & 1.80 & 1.00 to 3.24 & 1.79 & 1.27 to 2.51 \\
\hline Lowest & 1.94 & 1.39 to 2.71 & 2.53 & 1.37 to 4.67 & 1.93 & 1.35 to 2.75 \\
\hline \multicolumn{7}{|l|}{ Urbanisation } \\
\hline Urban & 1 & Ref. & 1 & Ref. & 1 & Ref. \\
\hline Rural & 1.08 & 0.86 to 1.24 & 0.79 & 0.49 to 1.25 & 1.18 & 0.92 to 1.50 \\
\hline $\begin{array}{l}\text { Random effect, intercept } \\
\text { variability (SE) }\end{array}$ & 0.116 & $(0.048)$ & 0.035 & $(0.172)$ & 0.079 & $(0.057)$ \\
\hline
\end{tabular}

*1847 Participants with missing data on parental education or municipality were not included in the analysis.

†RR in a model including gender, year of birth, parental education level, father's income level, mother's marital status, municipal proportion of high-income earners, and municipal urbanisation.

Considering the decreasing crude mortality by increasing income, this was unexpected. The main explanation is that the 17822 males with lowly educated parents (below completed upper secondary) and high-income fathers had a distinctive high non-collision driver death rate (21 driver deaths, rate 23.6). The 54273 males from families with both low income and education numbered 34 drivers in fatal non-collision crashes (rate 12.6).

The PAF estimates in the four gender-crash type categories in table 4 showed the same pattern as the RR estimates. Municipal disadvantage PAF estimates were 0.52 (95\% CI 0.04 to 0.78 ), 0.56 (95\% CI 0.14 to 0.77 ), 0.39 (95\% CI 0.15 to 0.56 ), and 0.48 ( $95 \%$ CI 0.26 to 0.64 ) for female non-collision, female collision, male non-collision, and male collision mortality, respectively. The only significant PAF estimates for family SEP indicators were found in the male non-collision category: 0.94 (95\% CI 0.59 to 0.99 ) for decreasing parental education and 0.25 (95\% CI 0.06 to 0.40 ) for increasing paternal income.

Table 4 also shows that the male non-collision death category was the only category with an increased RR in association with rural municipalities. Sons and daughters of unmarried mothers also had increased RRs in association with non-collision but not collision death.

\section{DISCUSSION}

Road traffic injury was a major cause of death in this young population and more than $90 \%$ were motor vehicle occupants. The highest male death rates were observed at an age when they were entitled to obtain a driver's license. In multilevel analysis taking individual factors into account, fatal motor vehicle injury rates increased with increasing levels of municipal disadvantage. Associations with family SEP indicators were almost only restricted to male non-collision deaths, showing steeply increasing mortality with decreasing levels of parental education and more moderate mortality increases by increasing levels of paternal income.

\section{Strengths and limitations}

This multilevel study was based on complete linkage between national registries, which renders selection bias an unlikely problem. Information bias and confounding are more plausible limitations when using national registries, as data are often collected for purposes other than research. There may be limitations related to data quality as well as a lack of information on potentially important factors. The time-at-risk data were approximates because we had no data on road traffic exposure. Ideally, driver's license information and individual driver and 
Table 4 Motor vehicle occupant death $(n=621)$ according to gender and type of crash, in association with individual and municipal characteristics, for 609807 Norwegians born between 1967 and 1976 and followed-up from age 16 to 20 years*

\begin{tabular}{|c|c|c|c|c|c|c|c|c|}
\hline \multirow[b]{3}{*}{ Characteristic } & \multicolumn{4}{|c|}{ Females } & \multicolumn{4}{|l|}{ Males } \\
\hline & \multicolumn{2}{|c|}{ Non-collision $\dagger$ (57 deaths) } & \multicolumn{2}{|c|}{ Collision† (71 deaths) } & \multicolumn{2}{|c|}{ Non-collision† (259 deaths) } & \multicolumn{2}{|c|}{ Collision $†$ (234 deaths) } \\
\hline & $\overline{\mathbf{R R} \ddagger}$ & $95 \% \mathrm{Cl}$ & $\overline{\mathbf{R R}} \ddagger$ & $95 \% \mathrm{Cl}$ & $\overline{\mathbf{R R}} \neq$ & $95 \% \mathrm{Cl}$ & $\overline{\mathbf{R R}} \neq$ & $95 \% \mathrm{Cl}$ \\
\hline \multicolumn{9}{|l|}{ Individual level variables } \\
\hline Year of birth & 0.90 & 0.81 to 1.00 & 0.94 & 0.80 to 1.11 & 0.93 & 0.88 to 0.97 & 0.92 & 0.87 to 0.96 \\
\hline \multicolumn{9}{|l|}{ Parental education level } \\
\hline Tertiary, high & 1 & Ref. & 1 & Ref. & 1 & Ref. & 1 & Ref. \\
\hline Tertiary, low & 0.36 & 0.07 to 1.86 & 0.90 & 0.28 to 2.90 & 3.06 & 0.91 to 10.27 & 1.10 & 0.51 to 2.36 \\
\hline Upper secondary, complete & 1.42 & 0.39 to 5.24 & 1.00 & 0.31 to 3.21 & 5.49 & 1.69 to 17.89 & 1.82 & 0.87 to 3.78 \\
\hline Upper secondary, basic & 1.08 & 0.29 to 3.98 & 1.17 & 0.38 to 3.59 & 6.73 & 2.09 to 21.68 & 1.53 & 0.74 to 3.16 \\
\hline Lower secondary or less & 1.37 & 0.34 to 5.44 & 0.93 & 0.26 to 3.29 & 10.24 & 3.13 to 33.49 & 1.83 & 0.85 to 3.93 \\
\hline \multicolumn{9}{|l|}{ Father's income quartile } \\
\hline Highest & 1 & Ref. & 1 & Ref. & 1 & Ref. & 1 & Ref. \\
\hline Third & 0.74 & 0.29 to 1.90 & 1.54 & 0.75 to 3.13 & 0.70 & 0.47 to 1.05 & 1.03 & 0.68 to 1.57 \\
\hline Second & 0.71 & 0.28 to 1.83 & 0.58 & 0.24 to 1.39 & 0.78 & 0.53 to 1.16 & 0.88 & 0.57 to 1.34 \\
\hline Lowest & 1.38 & 0.59 to 3.25 & 1.08 & 0.49 to 2.41 & 0.54 & 0.36 to 0.82 & 0.99 & 0.64 to 1.54 \\
\hline Missing & 1.34 & 0.44 to 4.04 & 1.21 & 0.40 to 3.67 & 0.85 & 0.50 to 1.43 & 1.43 & 0.81 to 2.52 \\
\hline \multicolumn{9}{|l|}{ Mother's marital status } \\
\hline Married & 1 & Ref. & 1 & Ref. & 1 & Ref. & 1 & Ref. \\
\hline Unmarried & 2.06 & 1.14 to 3.71 & 0.69 & 0.34 to 1.42 & 1.67 & 1.23 to 2.26 & 1.04 & 0.73 to 1.49 \\
\hline Missing & 1.41 & 0.19 to 10.36 & 0.29 & 0.04 to 4.27 & 2.18 & 1.02 to 4.66 & 1.87 & 0.82 to 4.25 \\
\hline \multicolumn{9}{|l|}{ Municipal level variables } \\
\hline \multicolumn{9}{|l|}{ Proportion high-income earners (quartiles) } \\
\hline Highest & 1 & Ref. & 1 & Ref. & 1 & Ref. & 1 & Ref. \\
\hline Third & 2.74 & 1.14 to 6.55 & 1.78 & 0.74 to 4.33 & 1.14 & 0.71 to 1.83 & 1.72 & 1.01 to 2.92 \\
\hline Second & 2.19 & 0.88 to 5.45 & 1.76 & 0.70 to 4.43 & 1.66 & 1.06 to 2.59 & 2.18 & 1.30 to 3.65 \\
\hline Lowest & 1.88 & 0.69 to 5.13 & 3.67 & 1.48 to 9.14 & 1.76 & 1.10 to 2.81 & 2.23 & 1.29 to 3.86 \\
\hline \multicolumn{9}{|l|}{ Urbanisation } \\
\hline Urban & 1 & Ref. & 1 & Ref. & 1 & Ref. & 1 & Ref. \\
\hline Rural & 1.15 & 0.54 to 2.43 & 0.61 & 0.31 to 1.20 & 1.66 & 1.20 to 2.29 & 0.72 & 0.49 to 1.07 \\
\hline Random effect, intercept variability (SE) & 0.000 & $(0.000)$ & 0.134 & $(0.323)$ & 0.086 & $(0.104)$ & 0.167 & $(0.123)$ \\
\hline
\end{tabular}

*1847 Participants with missing data on parental education or municipality were not included in the analysis.

†Non-collision: ICD-8 E816; ICD-9 E816; ICD-10 V28/V48: non-collision motor vehicle crash due to loss of control on the road. Collision: other motor vehicle crashes.

$\ddagger R R$ in a model including gender, year of birth, parental education level, father's income level, mother's marital status, municipal proportion of high-income earners, and municipal urbanisation.

passenger kilometres should have been available. ${ }^{13} 26$ The association with low paternal income could be underestimated if participants in low income families had less access to motor vehicles. Another shortcoming is lack of data that could be informative regarding risk-taking characteristics that might explain SEP gradients (eg, speeding, impaired driving, night driving, passenger influence, personal characteristics). ${ }^{1} 1926-28$ Finally, we based family SEP on parental education level and paternal income level, whereas occupational class data were unavailable. Occupational class has often been used in epidemiological studies addressing social inequalities in health, ${ }^{29}$ but parental education had highest impact on road traffic injuries among young car drivers in a Swedish study. ${ }^{14}$ Data error and blunt specification of register data is not likely to be dependent on quality of data from other sources. It is plausible that such non-differential error would attenuate true associations. Therefore, the lack of social gradients in collision and female deaths should be interpreted with caution.

We constructed municipal variables on the basis of available data in the regional base; data quality could be poorer for municipal than for individual variables. In general, misspecification of area data and adjustment for better measured individual level variables could result in underestimation of area level effects. ${ }^{30}$

\section{Relation to other studies}

Low socioeconomic level at the area or individual level has been shown to increase the risk of fatal or non-fatal traffic injuries in numerous studies. ${ }^{4}$ We found sharper socioeconomic gradients than in most other reports. This could perhaps be explained by differences in outcome definitions: the gradient could be stronger for more serious injuries than for less serious injuries, ${ }^{12}$ and stronger for road traffic injuries dominated by motor vehicle events than broader categories of transport-related injuries. ${ }^{11}$

Only a few studies have estimated area effects, taking individual factors into consideration. ${ }^{8-10}$ The association with municipal disadvantage in the present study is in agreement with findings in the US National Health Interview Survey. ${ }^{9}$ An opposite result was found in Stockholm county where injury odds among motor vehicle riders below age 17 decreased in association with increasing parish level deprivation. ${ }^{10}$ This discrepancy could be due to the low age and the probable domination of moped riders in the Swedish study.

The family SEP gradient in our study was restricted to males in non-collision crashes. To the best of our knowledge, there is only one other study addressing injury risk in young adults according to socioeconomic level, gender, and type of crash. ${ }^{12}$ Hasselberg et al ${ }^{12}$ found that single vehicle (comparable to noncollision) crash patterns showed some similarities with our findings, but the strength of associations and the clear distinction between single vehicle and other crash types were not found. It is also interesting that Hasselberg and Laflamme reported a reversal of the family income gradient in injury risk after adjustment for parental education, ${ }^{14}$ just as in our study.

The increased mortality in association with a rural residence is in agreement with several earlier reports, ${ }^{9} 1325$ and could be 
explained by more serious crashes as well as delayed receipt of medical care in remote areas. ${ }^{25}$ Moderate associations between road traffic injury and single parents have been reported in some studies. ${ }^{1031}$ This could be in accord with the moderate mortality excess among participants with unmarried mothers in our study. However, we found a specific association with female and male non-collision crashes, and this has, to the best of our knowledge, not been reported earlier.

\section{Interpretations and implications}

The results provide documentation that SEP gradients in road traffic mortality are diverse: there is an overall gradient according to neighbourhood disadvantage and a complex SEP gradient on the family level for male non-collision mortality. The documentation of diverse SEP gradients in this study, which covers a seemingly strictly defined outcome and a narrow age band, illustrates that the causal pathways linking social factors and health can be intricate. The gender-specific socioeconomic patterns are further indications of complex pathways between societal distribution of determinants and health outcomes. We believe that the results of the present study could prove useful in our general understanding of social inequalities in health.

There are several indications that high-risk behaviour partly explains the high rates and distinct socioeconomic pattern in male non-collision deaths. Causal models for road traffic injuries emphasise the division between exposure level and exposure susceptibility (risk proneness). ${ }^{4-7}$ The association with high levels of paternal income suggests increased car access and higher exposure (more kilometres) ${ }^{32}$ as part of the explanation. The association with a rural residence could also be explained by higher exposure, but speeding in remote areas could result in more fatalities per crash as well. ${ }^{25}$ Exposure surveys in Norway $^{33} 34$ suggest that a considerable portion of the male excess mortality cannot be explained by exposure level. Nor did exposure explain SEP gradients in road traffic injuries in Australia. ${ }^{13}$ Another Norwegian survey indicates that males are considerably more prone than females to exceed speed limits. ${ }^{35}$ Non-collision injuries among young males have been associated with impaired ${ }^{2627}$ and unlicensed ${ }^{26}$ driving in Swedish studies.

The strong negative association between parental education and fatal male non-collision crashes could be explained by a mediating mechanism. ${ }^{36}$ Adolescent psychosocial adjustment and risk-taking behaviour have been shown to predict novice traffic incidents. ${ }^{28}$ Increasing parental education level has been associated with parental support and child behavioural competence and coping. ${ }^{36}$ Furthermore, parental support and monitoring are related to adolescent risk-taking ${ }^{36}$ and crash levels. ${ }^{37}$ Accordingly, parental education could influence support and monitoring, which in turn could affect risk-taking behaviour and crash risk. ${ }^{36}$

Road safety strategies and legislation in Norway are similar to those in other developed European countries. ${ }^{3} 37$ Road traffic mortality among youths in developed countries is a leading cause of death and shows socioeconomic gradients, ${ }^{1-4}$ suggesting that results of the present study are not only valid for Norway. Mortality was decreasing for later born participants and we could question whether results from the follow-up during 1983-96 would be valid for more recent years. However, the relative dominance of road traffic deaths still prevails and socioeconomic gradients are not decreasing. ${ }^{2-4}$

Prevention of road traffic injuries is not given sufficient priority. ${ }^{1-4}$ The combined effects in the present study of municipal disadvantage and SEP gradients in the family suggest that both community-based and family interventions should be

\section{What is already known on the subject}

Motor vehicle injury is a main cause of death in the late teens and early twenties in high-income countries.

- There are socioeconomic inequalities in injury rates and mortality, but the relative contribution of area disadvantage and individual socioeconomic position is not clear.

\section{What this study adds}

- The socioeconomic pattern for mortality among motor vehicle occupants aged 16-20 years was distinctly different according to gender and crash type.

- There was a strong road traffic mortality gradient according to municipal degree of disadvantage. Male death after a noncollision crash was the only category showing strong socioeconomic gradients on the family level, with increased mortality for decreasing parental education level and high paternal income level.

- Community-based preventive programmes are important in order to reduce social inequalities in road traffic deaths in adolescence and young adulthood, but should be supplemented with more targeted actions aimed at the high-risk male group.

further strengthened. Graduated licensing policies have had effects in countries with a lower licensing age. ${ }^{38}$ Such policies could improve in effectiveness if parents were more strongly involved. $^{39}$

Acknowledgements We thank Ola Thune at the Norwegian Labour and Welfare Administration and Geir A Skjeret at Norwegian Armed Forces Medical Services for file preparations, and Karina Corbett at the National Institute of Occupational Health for language revision. Municipal level data used in this publication derived from the Norwegian Social Science Data Service regional database. The Norwegian Social Science Data Service is not responsible for the analysis of the data or the interpretations made here.

Funding The Research Council of Norway (grant no. 201334).

Competing interests: none declared

Ethics approval This study was conducted with the approval of the Regional Committee for Medical Research Ethics.

Contributors All authors meet the uniform requirements for manuscripts submitted to medical journals. TB and PK had the initial idea of the study and established the data file. PK was responsible for study design, analyses, and drafting the article. TB, TK, $M R$, and HMG oversaw the study design, contributed to interpretations of the findings, and participated in writing the article. TK and MR provided background information and reviewed the literature. All authors have seen and approved the final version of the paper.

Provenance and peer review Not commissioned; externally peer reviewed.

\section{REFERENCES}

1. Peden M, Scurfield R, Sleet D, et al, eds. World Report on Road Traffic Injury Prevention. Geneva: World Health Organization, 2004. http://whqlibdoc.who.int/ publications/2004/9241562609.pdf (accessed 28 Mar 2011)

2. Sethi D, Racioppi F, Baumgarten I, et al. Reducing inequalities from injuries in Europe. Lancet 2006;368:2243-50.

3. WHO. Global Status Report on Road Safety: Time for Action. Geneva: World Health Organization, 2009. http://whqlibdoc.who.int/publications/2009/ 9789241563840 eng.pdf (accessed 28 Mar 2011).

4. Laflamme L, Burrows S, Hasselberg M. Socioeconomic Differences in Injury Risks: A Review of Findings and a Discussion of Potential Countermeasures. Copenhagen: World Health Organization, 2009. http://www.euro.who.int/_ data/assets/pdf_file/ 0012/111036/E91823.pdf (accessed 28 Mar 2011). 
5. Laflamme L. Explaining socio-economic differences in injury risks. Inj Contr Saf Promot 2001;8:149-53

6. Laflamme $\mathbf{L}$, Diderichsen $\mathrm{F}$. Social differences in traffic injury risks in childhood and youth - a literature review and a research agenda. Inj Prev 2000:6:293-8.

7. Runyan CW. Introduction: back to the future - revisiting Haddon's conceptualization of injury epidemiology and prevention. Epidemiol Rev 2003:25:60-4.

8. Borrell C, Rodríguez M, Ferrando J, et al. Role of individual and contextual effects in injury mortality: new evidence from small area analysis. Inj Prev 2002;8:297-302.

9. Cubbin C, LeClere FB, Smith GS. Socioeconomic status and injury mortality: individual and neighbourhood determinants. J Epidemiol Community Health 2000;54:517-24.

10. Laflamme L, Hasselberg M, Reimers AM, et al. Social determinants of child and adolescent traffic-related and intentional injuries: a multilevel study in Stockholm County. Soc Sci Med 2009;68:1626-34.

11. Hasselberg $\mathbf{M}$, Laflamme L, Weitoft GR. Socioeconomic differences in road traffic injuries during childhood and youth: a closer look at different kinds of road user J Epidemiol Community Health 2001:55:858-62.

12. Hasselberg M, Vaez M, Laflamme L. Socioeconomic aspects of the circumstances and consequences of car crashes among young adults. Soc Sci Med 2005:60:287-95.

13. Chen HY, Ivers $\mathrm{RO}$, Martiniuk $\mathrm{AL}$, et al. Socioeconomic status and risk of car crash injury, independent of place of residence and driving exposure: results from the DRIVE Study. J Epidemiol Community Health 2010;64:998-1003.

14. Hasselberg M, Laflamme L. Socioeconomic background and road traffic injuries: a study of young car drivers in Sweden. Traffic Inj Prev 2003:4:249-54.

15. Laflamme L, Engström K. Socioeconomic differences in Swedish children and adolescents injured in road traffic incidents: cross sectional study. BMJ 2002:324:396-7.

16. Zambon F, Hasselberg M. Socioeconomic differences and motorcycle injuries: age at risk and injury severity among young drivers: a Swedish nationwide cohort study. Accid Anal Prev 2006:38:1183-9.

17. Reimers $\mathbf{A M}$, de Leon AP, Laflamme L. The area-based social patterning of injuries among 10 to 19 year olds changes over time in the Stockholm County. BMC Public Health 2008:8:131.

18. Pless IB, Peckham CS, Power C. Predicting traffic injuries in childhood: a cohort analysis. J Pediatr 1989:115:932-8.

19. Batty GD, Gale CR, Tynelius P, et al. IO in early adulthood, socioeconomic position, and unintentional injury mortality by middle age: a cohort study of more than 1 million Swedish men. Am J Epidemiol 2009:169:606-15.

20. Whitlock G, Norton R, Clark T, et al. Motor vehicle driver injury and socioeconomic status: a cohort study with prospective and retrospective driver injuries. J Epidemiol Community Health 2003:57:512-16.

21. Siegrist J, Marmot M. Introduction. In: Siegrist J, Marmot M, eds. Social Inequalities in Health: New Evidence and Policy Implications. New York, NY: Oxford University Press, 2006:1-25.

22. West $\mathbf{P}$. Health inequalities in the early years: is there equalisation in youth? Soc Sci Med 1997:44:833-58.

23. Goldman N. Social inequalities in health: disentangling the underlying mechanisms. Ann N Y Acad Sci 2001;954:118-39.
24. Gravseth HM, Mehlum L, Bjerkedal T, et al. Suicide in young Norwegians in a life course perspective: population based cohort study. J Epidemiol Community Health 2010;64:407-12.

25. Zwerling C, Peek-Asa C, Whitten PS, et al. Fatal motor vehicle crashes in rural and urban areas: decomposing rates into contributing factors. Inj Prev 2005:11:24-8

26. Hasselberg $\mathbf{M}$, Laflamme L. How do car crashes happen among young drivers aged 18-20 years? Typical circumstances in relation to license status, alcohol impairmen and injury consequences. Accid Anal Prev 2009:41:734-8.

27. Vaez M, Laflamme L. Impaired driving and motor vehicle crashes among Swedish youth: an investigation into drivers' sociodemographic characteristics. Accid Anal Prev 2005:37:605-11.

28. Shope JT, Raghunathan TE, Patil SM. Examining trajectories of adolescent risk factors as predictors of subsequent high-risk driving behavior. J Adolesc Health 2003; 32:214-24

29. Galobardes B, Shaw M, Lawlor DA, et al. Indicators of socioeconomic position (part 1). J Epidemiol Community Health 2006:60:7-12.

30. Diez Roux AV. Next step in understanding the multilevel determinants of health. J Epidemiol Community Health 2008;62:957-9.

31. Weitoft GR, Hjern A, Haglund B, et al. Mortality, severe morbidity, and injury in children living with single parents in Sweden: a population-based study. Lancet 2003;361:289-95.

32. Stangeby I, Haukeland JV, Skogli A. Travel Behaviour in Norway 1998. TØI report 418/1999 [In Norwegian, English summary]. Oslo: Institute of Transport Economics, 1999. http://www.toi.no/getfile.php/Publikasjoner/T\%D8l\%20rapporter/1999/4181999/418-1999-el.pdf (accessed 28 Mar 2011).

33. Bjørnskau T. Road Traffic Risk in Norway 2005-2007. Tø। report 986/2008 [In Norwegian, English summary]. Oslo: Institute of Transport Economics, 2008. http:// www.toi.no/getfile.php/Publikasjoner/T\%D8|\%20rapporter/2008/986-2008/9862008-internett.pdf (accessed 28 Mar 2011).

34. Bjørnskau T. Road Traffic Exposure and Risk Among High Risk Groups. TØl report 1042/2009 [In Norwegian, English summary]. Oslo: Institute of Transport Economics, 2009. http://www.toi.no/getfile.php/Publikasjoner/T\%D81\%20rapporter/2009/1042 2009/1042-2009-nett.pdf (accessed 28 Mar 2011).

35. Backer-Grøndahl A. Speeding: Attitudes, Knowledge and Behaviour. TØ। report 1005/2009 [In Norwegian, English summary]. Oslo: Institute of Transport Economics, 2009. http://www.toi.no/getfile.php/Publikasjoner/T\%D81\%20rapporter/2009/10052009/1005-2009-nett.pdf (accessed 28 Mar 2011)

36. Wills TA, McNamara G, Vaccaro D. Parental education related to adolescent stress coping and substance use: development of a mediational model. Health Psychol 1995; 14:464-78

37. Twisk DA, Stacey C. Trends in young driver risk and countermeasures in European countries. J Safety Res 2007;38:245-57.

38. Hartling L, Wiebe N, Russell K, et al. Graduated driver licensing for reducing motor vehicle crashes among young drivers. Cochrane Database Syst Rev 2004;(2): CD003300.

39. Simons-Morton B. Parent involvement in novice teen driving: rationale, evidence of effects, and potential for enhancing graduated driver licensing effectiveness. J Safety Res 2007;38:193-202.

\section{A surprising impaired driving charge}

Quebec police arrested a drunk driver who suddenly veered from one lane to the other, striking a car and seriously injuring the driver who had to be extracted using the 'Jaws of Life'. So far, this story is too much like so many others to offer any surprises. There are, however, two twists to the story: the first is that the intoxicated driver was a Quebec police officer. He was charged with impaired driving causing bodily harm. The second? The drunken officer was driving a police car!

\section{Are the Chinese good or careless drivers?}

It seems that much depends on where in China you are: Beijing drivers behave differently than others, for example, where it is customary to ignore traffic lights entirely. Similarly, policing is variable but generally indifferent. http://en.radio86.com/lifestyle-china/dial-beijing/dial-beijingpublic-transportation-safety-china 